\title{
PAIS, FILHOS E PADRINHOS NO SUL FLUMINENSE, SÉCULO XIX
}

Marcia Cristina de Vasconcellos*

$\mathrm{N}$ os últimos trinta anos, houve uma revisão da historiografia sobre a escravidão: o cativo passou a ser compreendido como um sujeito histórico que obteve conquistas em meio às brechas do sistema. ${ }^{1}$ Da mesma forma, a ideia de promiscuidade foi reformulada, e comprovou-se a existência de laços familiares. ${ }^{2}$ Este é o tema do presente artigo, tendo como recorte espacial a cidade de Angra dos Reis, no litoral sul-fluminense, ao longo do século XIX. Analisaremos as famílias formadas por escravos em meio a um quadro de transformações econômicas e demográficas.

Antes de conhecermos um pouco a localidade em estudo, faz-se necessário apresentar o conceito de família aqui empregado. Trata-se de uma construção histórica, tal como afirma Sheila Faria, e leva em conta a consanguinidade, os laços de amizade e de compadrio. ${ }^{3}$ No caso dos escravos, dos anos de 1990 até a atualidade, diversas pesquisas confir-

* Professora da UNIABEU Centro Universitário. marciavasconcellos3@gmail.com

João José Reis e Eduardo Silva, Negociação e conflito, São Paulo: Companhia das Letras, 1989, p. 151.

2 Dentre outros: Manolo Garcia Florentino e Roberto de Góes, A paz das senzalas, Rio de Janeiro: Nova Fronteira, 1997, p. 256; Robert Slenes, Na senzala, uma flor, Rio de Janeiro: Nova Fronteira, 1999, p. 288; Hebe Maria Mattos de Castro, Das cores do silêncio, Rio de Janeiro: Arquivo Nacional, 1995, p. 426; José Flávio Motta, Corpos escravos, vontades livres, São Paulo: FAPESP/Annablume, 1999, p. 426.

3 Sheila de Castro Faria, A colônia em movimento, Rio de Janeiro: Nova Fronteira, 1998, p. 432. 
maram sua existência. Os estudos observaram variações nas formas de organização parental em função do número de trabalhadores por propriedade, foram localizados grupos parentais incluindo até três gerações e constatada uma tendência à não separação das famílias no momento de partilha dos inventários. Verificou-se, também, que os cativos aparentados consideravam a alforria um projeto familiar. ${ }^{4}$ No entanto, há uma discussão acerca do papel dos vínculos parentais para senhores e cativos.

Para Manolo Garcia Florentino e José Roberto Góes, a intensa chegada de africanos, considerados estrangeiros, criava um campo de conflito, contornado mediante a criação de laços familiares, quando o desconhecido tornava-se conhecido e, assim, fundando-se a paz. Dessa forma, as famílias auxiliavam na reprodução do sistema escravista, tendo um papel estrutural. ${ }^{5}$

Essa perspectiva foi criticada por Robert Slenes. Ele acredita que a família, embora respondesse a uma estratégia senhorial de formação de reféns, tanto dos anseios dos escravos quanto dos proprietários, apresentou-se como espaço por meio do qual experiências e memórias eram transmitidas. Os grupos parentais facilitavam o aparecimento de autonomia entre os cativos e tinham uma função "desestabilizadora". ${ }^{6}$

Hebe Maria Mattos de Castro, a sua vez, considerou que, ao contrário de estar relacionada com a vivência do cativeiro, à medida que se favorecia a obtenção de roças e moradias separadas, os escravos

\footnotetext{
4 Dentre outros: Roberto Guedes Ferreira, "Na pia batismal. Família e compadrio entre escravos na freguesia de São José do Rio de Janeiro (primeira metade do século XIX)" (Dissertação de Mestrado, Universidade Federal Fluminense, 2000), p. 225; Marcia Cristina de Vasconcellos, "Nas bênçãos de Nossa Senhora do Rosário. Relações familiares entre escravos em Mambucaba, Angra dos Reis, 1830 a 1881" (Dissertação de Mestrado, Universidade Federal Fluminense, 2001), p. 194; José Roberto de Góes, "Escravos da paciência. Estudo da obediência escrava no Rio de Janeiro (1790-1850)" (Tese de Doutorado, Universidade Federal Fluminense, 1998), p. 386; Cristiany Miranda Rocha, Histórias de famílias escravas, Campinas: Editora da UNICAMP, 2004, p. 181; Carlos Engeman, De laços e de nós, Rio de Janeiro: Apicuri, 2008, p. 200; Cristiane Pinheiro Santos Jacinto, Laços e enlaces, São Luís: EDUFMA, 2008, p. 186; Solange Pereira da Rocha, Gente negra na Paraíba oitocentista, São Paulo: Ed. UNESP, 2009, p. 332; Jorge Prata de Sousa e Rômulo Garcia de Andrade (orgs), Zona da Mata mineira: escravos, família e liberdade (Rio de Janeiro: Apicuri, 2012), p. 204. Como trabalho de síntese, ver: Francisco Vidal Luna e Herbert Klein, Escravismo no Brasil, São Paulo: EDUSP, 2010, p. 400.

Florentino \& Góes, $A$ paz.

6 Slenes, Na senzala.
} 
envoltos em laços familiares adquiriam certo destaque junto à escravaria e aproximavam-se do "mundo" dos livres."

\section{Angra dos Reis: breve histórico}

Angra dos Reis ${ }^{8}$ foi uma das primeiras áreas a que os portugueses chegaram, na costa sul de São Sebastião do Rio de Janeiro, no ano de 1502. ${ }^{9}$ Em fins do século XVI, os poucos colonos dedicavam-se à produção de alimentos e de cana-de-açúcar. No século XVIII, com a descoberta de ouro e diamantes nas Minas Gerais, o litoral sul-fluminense destacou-se no cenário colonial, pois a saída de metais e pedras preciosas e a entrada de mercadorias e de escravos ocorriam, até meados da centúria, pelo Caminho Velho ou dos Guaianazes. ${ }^{10}$ Segundo Antonil, ia-se do Rio de Janeiro, por mar, até Parati, de onde seguia-se para Taubaté, Pindamonhangaba, Guaratinguetá, até as roças de Garcia Rodrigues e, finalmente, ao Rio das Velhas. ${ }^{11} \mathrm{O}$ movimento portuário dinamizou a vila de Parati e, indiretamente, Angra dos Reis, para onde iam os "descaminhos" do ouro. Corsários, como franceses, ingleses e holandeses, circulavam pela Baía da Ilha Grande, atraídos pelo metal. A Coroa portuguesa, preocupada com o contrabando, autorizou a construção de um novo caminho, exclusivamente terrestre, que ligava o Rio de Janeiro a Minas. Dessa forma, houve uma retração do fluxo pelo Caminho Velho, mas Parati e Angra dos Reis continuaram vinculadas à "história" do ouro, pois foram abertos caminhos paralelos (clandestinos) em direção aos portos da região sul-fluminense. Ao mesmo tempo, a cultura da cana disseminou-se na região, e a produção de aguardente tornou-se comum, além da de arroz, feijão e mandioca. ${ }^{12}$

\footnotetext{
Castro, Das cores.

O nome que constava nos documentos oficiais, até meados do século XVII, era Nossa Senhora da Conceição. Posteriormente, passou a chamar-se Vila da Ilha Grande. A partir de 1835, quando a vila foi elevada à cidade, recebeu o nome de Angra dos Reis. Ver: Camil Capaz, Memórias de Angra dos Reis, Rio de Janeiro: Edição do autor, 1996, p. 220.

9 Alípio Mendes, Angra dos Reis. Da criação da vila até sua transferência para a atual cidade (1502-1624), Angra dos Reis: Ateneu Angrense de Letras de Letras e Artes, 1995, p. 352.

10 Marina de Mello e Souza, Parati: a cidade e as festas, Rio de Janeiro: Editora da UFRJ, 1994, p. 261.

1 Souza, Parati, p. 37.

12 Marcia Cristina de Vasconcellos, "Famílias escravas em Angra dos Reis, 1801-1888" (Tese de Doutorado, Universidade de São Paulo, 2006), p. 273.
} 
Em fins do século XVIII, com o início da cafeicultura, novo impulso foi dado ao litoral, estando, mais uma vez, vinculado ao movimento portuário. À medida que os cafezais foram se espalhando pelo Vale do Paraíba fluminense e paulista, os portos de Parati e, em destaque, os de Angra dos Reis, tornaram-se locais de escoamento do café em direção ao Rio de Janeiro. Vias foram recuperadas e outras foram abertas, ligando o litoral ao vale. Tropas de São João Marcos, Resende, Piraí, Bananal e Areias chegavam a Parati, Angra e Mangaratiba. Com isso, moradores se tornaram marinheiros, o excedente da produção local passou a ser vendido aos homens que subiam e desciam a Serra do Mar, e foram instalados armazéns de café. ${ }^{13}$

Não obstante, após os anos de $1850,{ }^{14}$ houve uma redução da atuação portuária local, em decorrência da construção da Estrada de Ferro D. Pedro II, que se tornou responsável pelo transporte do café do Vale do Paraíba até a Corte, além do aumento da participação do porto de Santos nas exportações. Na mesma época, foi abolido o tráfico de escravos africanos, embora tenham ocorrido alguns desembarques, particularmente no litoral sul-fluminense, como o famoso Caso do Bracuhy, em 1852, envolvendo o Comendador Joaquim José de Sousa Breves e Manuel de Aguiar Vallim, na freguesia da Ribeira, em Angra dos Reis. ${ }^{15}$ No entanto, ao longo do tempo, diminuiu a importação de africanos, levando, grosso modo, ao aumento do preço dos cativos e ao incremento do tráfico inter e intraprovincial. ${ }^{16} \mathrm{Em}$ decorrência de tais acontecimentos, a população angrense começou a sofrer com uma crise econômica que só foi revertida na segunda década do século XX. Ao lado disso, ocorreu uma transformação demográfica na região. ${ }^{17}$

\footnotetext{
13 Vasconcellos, "Famílias escravas", p. 49

14 O ano de 1850 é considerado como o da consolidação do Império, data da Lei Eusébio de Queiróz, que determinava o fim do tráfico de escravos; da Lei de Terras, que obrigava o registro das terras e a compra de terras devolutas, dentre outras; a reformulação da Guarda Nacional; e a criação do Código Comercial do Império. Ver: Marcelo Basile, "Consolidação e crise do Império", in Maria Yedda Linhares (org). História Geral do Brasil (Rio de Janeiro: Campus, 2000), p. 445; José Murilo de Carvalho, I-A construção da ordem, Rio de Janeiro: Editora da UFRJ, 1996, p. 436; e Ilmar Rohloff de Mattos, O tempo saquarema, Rio de Janeiro: ACCESS, 1994, p. 285.

15 Marta Abreu, "O caso do Bracuhy", in Hebe Maria Mattos de Castro e Eduardo Schnoor (orgs.), Resgate (Rio de Janeiro: Topbooks), 1995, p. 252.

16 Sobre o tráfico interno: José Flávio Motta, Escravos daqui, dali e de mais além, São Paulo: Alameda, 2012, p. 390.

17 Vasconcellos, "Famílias escravas".
} 
Entre os anos de 1840 e 1856, houve um crescimento anual da população livre de 2,02\%, enquanto, entre os cativos, ocorreu um decréscimo de $0,55 \%$. De 1856 a 1872, os livres cresceram a uma taxa de $0,25 \%$ ao ano, e o número de escravos reduziu-se em $4,60 \%,{ }^{18}$ isto é, durante a primeira metade do século XIX, a elevação numérica de livres foi maior do que após a década de 1850. Esse comportamento esteve associado ao dinamismo econômico vinculado aos portos angrenses. Durante os anos em que o café escoava por Angra dos Reis, instalaram-se armazéns e representantes de comerciantes fixados na praça mercantil do Rio de Janeiro, contexto que teria estimulado a migração rumo à região. Após 1850, quando se reduziu a atividade comercial, a região tornou-se menos atrativa. Quanto aos escravos, chama a atenção a grande redução numérica na segunda metade do século. Alguns angrenses tiveram mais dificuldades em adquirir braços, em função do aumento do preço dos cativos; outros, com dificuldades econômicas, venderam seus escravos para as áreas de ponta da economia imperial. ${ }^{19} \mathrm{Além}$ do mais, devem ser levados em conta os óbitos e as alforrias.

Em 1840, o número total de escravos correspondeu a 10.552; em 1850, a 10.480; em 1856, a 9.659; e, em 1872, reduziu-se a 4.544. Consequentemente, sua participação sobre a população total diminuiu: se, em 1840 , representavam $46,7 \%$, em 1872 , esse percentual chegou a $20,9 \% \cdot{ }^{20}$ Os dados constam na Tabela 1 .

Para o presente estudo, ${ }^{21}$ estabelecemos as faixas de tamanho das

\footnotetext{
18 Relatórios de Presidentes de Província do Rio de Janeiro, 1841, 1851 e 1858, Biblioteca Nacional (BN), Seção de Microfilmes. Censo Nacional de 1872, Instituto Histórico e Geográfico Brasileiro (IHGB).

19 Sobre as vendas de escravos para outras áreas, destacamos as informações contidas no Jornal do Comércio, dos meses de março, setembro, outubro e novembro dos anos de 1827 a 1888. Na parte relativa às entradas no porto do Rio de Janeiro, o periódico informava os nomes das embarcações, suas procedências, as cargas e os nomes dos passageiros. Observando os barcos vindos do litoral sul-fluminense, encontramos "escravos a entregar": de 1830 a 1839 chegaram 88 "escravos a entregar"; entre 1840 e 1849,198 ; entre 1850 e 1859, 459; entre 1860 e 1869 , 531 ; nos anos de 1870 a 1879,380 , incluindo cinco ingênuos; e de 1880 até 1888 , 22 cativos. Embora não saibamos se esses escravos vinham do litoral ou do interior, acreditamos que muitos tenham saído de Angra, Parati ou Mangaratiba, o que confirmaria a perda de escravos em Angra em função da venda. Para saber mais: Vasconcellos, "Famílias escravas", p. 63. O Jornal do Comércio foi localizado na Biblioteca Nacional (BN), Seção de Microfilmes.

20 Relatórios de Presidentes de Província do Rio de Janeiro, 1841, 1851 e 1858, op. cit., Censo Nacional de 1872, op. cit.

${ }^{21}$ Em vinte e cinco inventários não havia escravos avaliados.
} 


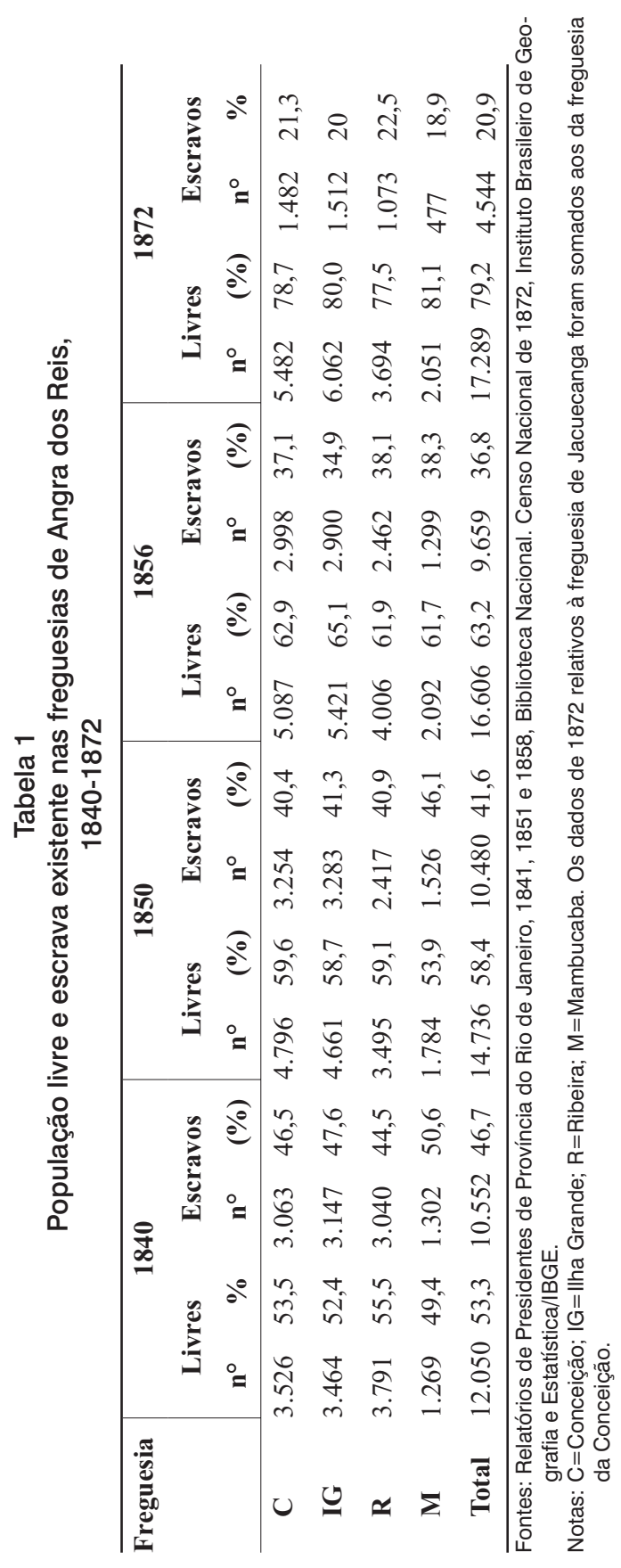

140 Afro-Ásia, 49 (2014), 135-158 
Tabela 2

Faixa de tamanho das propriedades por subperíodos Angra dos Reis, 1805-1871

\begin{tabular}{|c|c|c|c|c|c|c|}
\hline \multirow[t]{2}{*}{ FTP } & \multicolumn{2}{|c|}{$1800-1848$} & \multicolumn{2}{|c|}{ 1849-1872 } & \multicolumn{2}{|c|}{ Total } \\
\hline & $\mathbf{n}^{\mathbf{o}}$ & $\%$ & $n^{0}$ & $\%$ & $n^{0}$ & $\%$ \\
\hline $1-5$ & 42 & 47,7 & 57 & 53,3 & 99 & 50,7 \\
\hline $6-20$ & 28 & 31,8 & 33 & 30,8 & 61 & 31,3 \\
\hline 21 ou mais & 18 & 20,5 & 17 & 15,9 & 35 & 17,9 \\
\hline Total & 88 & 100,0 & 107 & 100,0 & 195 & 100,0 \\
\hline
\end{tabular}
(Museu da Justiça do Estado do Rio de Janeiro).

propriedades (FTP), utilizando, para tanto, as informações disponíveis em 195 inventários, dos 220 recolhidos no Museu da Justiça do Rio de Janeiro, como mostra a Tabela 2.

Na primeira metade do século, plantéis com um a cinco escravos chegaram a $47,7 \%$ e, na segunda, a 53,3\%. Já as grandes escravarias, com 21 ou mais cativos, representaram, respectivamente, $20,5 \%$ e $15,9 \%$. As médias propriedades, aquelas com seis a 20 trabalhadores, corresponderam a $31,8 \%$ e $30,8 \%$. Isto é, comparando-se os dois recortes temporais, observa-se o predomínio dos pequenos plantéis, corroborando as conclusões obtidas em outros estudos acerca das faixas de tamanho de plantéis em diferentes áreas do Brasil. ${ }^{22}$

\section{O batismo}

Ritual responsável pela purificação do pecado original, o sacramento do batismo oferecia ao pagão a passagem ao cristianismo, sendo-lhe conferido um nome cristão ou de um santo, tornando-o apto a participar das cerimônias da Igreja, além de adquirir igualdade, humanidade e liberdade.$^{23}$ Segundo Silvia Brugger, "o batismo constituiu-se no principal

Conferir Mota, Corpos escravos, pp. 65-108

23 Silvia Maria Jardim Brugger, Minas patriarcal: família e sociedade (São João del Rei-séculos XVIII e XIX), São Paulo: Annablume, 2007, p. 382. 
sacramento da religião católica, na medida em que marcava o ingresso do indivíduo na comunidade cristã e a remissão do pecado original". ${ }^{24}$ Existiam determinadas regras na ocasião da escolha dos "pais espirituais", forma como eram entendidos os padrinhos e as madrinhas: não poderiam ser os pais carnais e deveriam ser batizados e conhecedores da doutrina católica. A eles caberia a formação moral dos afilhados, pois seriam responsáveis por sua educação espiritual. ${ }^{25}$

Entre os registros de batismo do município em estudo, de um total de 3.264 envolvendo inocentes, encontramos oito registros em que os proprietários aparecem como padrinhos de seus próprios escravos, ${ }^{26}$ compreendendo $0,2 \%$ dos sacramentos. ${ }^{27} \mathrm{O}$ mesmo padrão foi verificado em várias localidades, como Campos dos Goitacazes, nos séculos XVII e XVIII $;^{28}$ na freguesia de São José, no Rio de Janeiro, na primeira metade do século XIX; $;^{29}$ e em São João Del Rei, entre 1736 e 1850, quando, em $1,1 \%$ das cerimônias, os senhores foram padrinhos de seus cativos. ${ }^{30}$

Além da conversão do pagão, as cerimônias e os registros de batismo desempenharam algumas funções práticas, como registrar por escrito a posse de escravos, doações, concessões de alforrias e até a comunicação de compra dos batizandos. Casos de doações com assinatura, inclusive de testemunhas, foram encontrados em vinte e um registros, correspondendo a $0,6 \%$. Onze batizandos foram doados aos filhos dos

\footnotetext{
24 Brugger, Minas patriarcal, p. 283.

25 François Lebrun, "O sacerdócio, o príncipe e a família", in André Burguière et alii, $O$ choque das modernidades: Ásia, África, América e Europa, v. 3 (Lisboa, Terramar, 1998), p. 89.

26 Góes, em estudo sobre Inhaúma, freguesia rural do Rio de Janeiro, considera que não havia incompatibilidade entre batismo e escravidão, tanto durante a colônia, quanto no império; Brugger, por sua vez, embora não tenha localizado proprietários apadrinhando seus escravos, encontrou parentes dos primeiros como padrinhos e madrinhas dos segundos, resultante de uma sociedade patriarcal. Em estudo sobre a freguesia de Mambucaba também encontramos parentes de senhores apadrinhado seus cativos. Ver: José Roberto de Góes, O cativeiro imperfeito, Vitória: Lineart, 1993, p. 209; Brugger, Minas patriarcal; Vasconcellos, "Nas bênçãos".

27 Livro de batismos de escravos de Mambucaba, 1830-1871, Convento do Carmo de Angra dos Reis (CCAR), RJ; Livro de batismos de escravos da Ribeira, 1824-1826, Igreja de Jacuecanga, Angra dos Reis (IJAR), RJ; Livros de batismos de escravos da Ilha Grande de 1805-1847 e de 1850-1861 e Livro de batismos, casamentos e óbitos de escravos e de livres de Jacuecanga, 1800-1888, Igreja de Jacuecanga, Angra dos Reis (IJAR), RJ.

28 Faria, A colônia, 1998, p. 310.

29 Ferreira, "Na pia batismal". p. 187

30 Brugger, Minas patriarcal, p. 286.
} 
senhores; sete, aos netos; duas, aos sobrinhos; e uma, a uma irmã. O batizado de Caetana, em 1861, na Igreja Matriz da Ilha Grande, ilustra o que foi dito. A inocente, nascida a 15 de janeiro daquele ano, era filha de Generosa africana, ambas cativas de Felisbino Martins, que, no ato do batismo, doou Caetana ao seu filho Benedito Martins da Silva. ${ }^{31}$

Dos 3.264 batismos ocorridos no período 1805-1871, houve uma média de 49,4 cerimônias ao ano. A maior parte ocorreu nas igrejas das freguesias, num total de 3.209 (98,3\%), enquanto $55(1,7 \%)$ foram realizados em residências e em fazendas dos proprietários.

Quanto ao ato do batismo, os simples foram 2.984 (91,4\%) contra $280(8,6 \%)$ coletivos. No caso dos primeiros, havia referência a uma única criança em um registro, enquanto os classificados como coletivos corresponderam a registros em que os párocos anotaram a conversão de dois ou mais batizandos, o que nos leva a crer na existência de algum grau de interferência senhorial na escolha da data da cerimônia. A ser verdade, poderíamos supor que as cerimônias ditas simples teriam sido manifestação da vontade cativa, visível, por exemplo, na escolha de padrinhos e madrinhas, embora não se possa descartar a atuação de senhores, já que os escravos eram, por definição, propriedade de outrem.

Com o batismo de inocentes, era criado um duplo laço: o de compadrio, envolvendo os pais e os padrinhos, e o de apadrinhamento, celebrando a associação entre batizandos e padrinhos. A escolha dos padrinhos era feita pelos pais dos batizandos, escolha que definia estratégias e objetivos que variavam de acordo com os participantes, suas situações jurídicas e a legitimidade dos batizandos. Esse vínculo, além de selecionar "pais espirituais", criava e reforçava amizades, solidariedades e conhecimentos. Entretanto, não fica descartada a possibilidade de interferência senhorial, estimulando, por exemplo, o compadrio entre seus cativos ou deles com escravos de outras propriedades.

A partir das fontes consultadas, a criança foi aqui identificada como ilegítima com base nas anotações: filho "natural", de "pai incógnito" ou de mãe solteira. Foram identificadas como filhos legítimos os batizandos em

\footnotetext{
31 Livro de batismos de escravos da Ilha Grande, 1850-1871, op. cit.
} 
cujos registros estavam indicados os nomes de seus pais, deixando-se implícito tratar-se de casais unidos perante a Igreja. Dessa forma, quando aludimos a comportamentos dos pais, estamos nos referindo a famílias formadas pelo sacramento do casamento e, quando nos referimos a mães solteiras, estamos falando de mulheres que se tornaram mães sem ter passado pela união legal. ${ }^{32}$

No total, 2.473 (77\%) crianças ilegítimas receberam o sacramento do batismo, sendo 742 (23\%) as legítimas. Entre os anos de 1805 e 1848, foram batizadas 523 (31,5\%) filhos legítimos e 1.137 (68,5\%) ilegítimos e, de 1848 a 1871, $219(14,1 \%)$ e $1.336(85,9 \%)$, respectivamente..$^{33} \mathrm{O}$ aumento da presença de crianças ilegítimas resultou, em geral, da diminuição de famílias legitimadas pelo casamento, com o consequente crescimento de famílias encabeçadas por mães solteiras. ${ }^{34}$

Nos anos anteriores a 1850, o percentual encontrado para Angra dos Reis foi menor que o documentado para Inhaúma, freguesia rural do Rio de Janeiro, entre 1817 e 1842, na qual as crianças naturais batizandas foram $887(79,3 \%){ }^{35}$

A grande maioria das crianças de Angra dos Reis, quer legítimas quer ilegítimas, foi batizada quando tinha até seis meses de nascimento. Dos batizandos legítimos, no período de 1805 a 1848, 413 (91\%) tinham menos de seis meses; 33 (7,3\%), de sete meses a um ano; e oito $(1,7 \%)$, um ano e um mês em diante. Entre 1849 e 1871, os percentuais foram de 70,7\% (152), 16,3\% (35) e 13\% (28), respectivamente. Entre os ilegítimos, $891(89,4 \%)$ foram encaminhados à pia batismal com até seis meses; 76 (7,6\%), com sete meses a um ano; e 30 (3\%) com um ano em diante, entre 1805 e 1848. Entre os anos de 1849 e 1871, os percentuais foram de 61,1\% (797), 23,2\% (302) e 15,7\% (205), respectivamente. ${ }^{36}$

Em vista da alta taxa de mortalidade infantil, o batismo era providenciado tão logo fosse possível o comparecimento do recém-nascido à cerimônia. Dessa forma, evitava-se sua morte sem a devida

32 Vasconcellos, "Famílias escravas".

33 Em 49 cerimônias não conseguimos identificar o grau de legitimidade dos batizandos.

34 Vasconcellos, "Famílias escravas", pp. 113-41.

35 Góes, O cativeiro, p. 59. Número abaixo das 3.293 (93,2\%) crianças ilegítimas presentes na pia batismal, na freguesia urbana de São José, no Rio de Janeiro, entre 1802-1821. Ferreira, "Na pia batismal", p. 147.

36 Não foram contabilizados 73 registros de legítimos e 172 de ilegítimos por falta de dados. 
conversão ao cristianismo, permitindo-lhe a entrada no reino dos céus. ${ }^{37}$ Tal preocupação pode ser vista, por exemplo, nos batismos ministrados aos recém-nascidos "em perigo de vida", realizados às pressas, muitas vezes em residências e sem a presença de padrinhos e madrinhas. De seis casos localizados, o batismo de Manoel, de um mês, em Jacuecanga, serve de exemplo. O pequeno foi batizado em 1861, em residência de seu proprietário, o Comendador Manoel Teixeira da Cunha, não havendo a nomeação de padrinho ou de madrinha. No registro, consta a observação: "batizado em casa em perigo de vida". ${ }^{38}$ Além disso, deve-se destacar a pressa de alguns senhores em legitimar a posse de recém-nascidos, providenciando com rapidez as cerimônias batismais.

A partir da comparação dos percentuais acima mencionados, observamos que os batismos de crianças legítimas com até seis meses eram ligeiramente mais frequentes que os das ilegítimas. Parece-nos que tal comportamento resultava de uma maior urgência dos pais em adotar vínculos de compadrio. Verificamos também que, independentemente da condição conjugal de seus pais, a segunda metade dos Oitocentos foi marcada pelo adiamento da conversão das crianças, fruto, possivelmente, de dificuldades encontradas pelos genitores em encaminhar seus rebentos à pia batismal.

Uma outra diferença entre os batismos de legítimos e de ilegítimos, é que, entre os primeiros, havia um ligeiro predomínio de padrinhos escravos, correspondendo a 52,2\%, no período $1805-1871$; os livres foram escolhidos em $41,1 \%$ das cerimônias; e os forros, em $6,7 \%$. Se examinarmos os dados para a primeira e a segunda metade do século, notamos que: os escravos estavam anotados em $47,4 \%$ dos registros até 1848 e, de 1849 em diante, em 63,6\%; os forros, respectivamente, em $7 \%$ e $6 \%$; e os livres, em $45,6 \%$ e 30,4\% (Tabela 3). Ou seja, paralelamente à diminuição numérica de escravos em Angra dos Reis, em decorrência de vendas, alforrias, mortes e fugas, os pais preocuparam-se, cada vez mais, em convidar escravos para se tornarem seus compadres, com vistas a garantir, no interior da comunidade, "pais espirituais" que poderiam auxiliá-los na criação de seus filhos.

37 Lebrun, "O sacerdócio", p. 89.

${ }^{38}$ Livro de batismos, de casamentos e de óbitos de livres e escravos de Jacuecanga, 1800-1871, op. cit. 
Tabela 3

Situação social de padrinhos de crianças escravas legítimas

por subperíodos

Angra dos Reis, 1805-1871

\begin{tabular}{l|cc|cc|cc|cc}
\hline Subperíodos & \multicolumn{2}{|c|}{ Escravos } & \multicolumn{2}{c|}{ Forros } & \multicolumn{2}{c|}{ Livres } & \multicolumn{2}{c}{ Total } \\
& $\mathbf{n}^{\mathbf{0}}$ & $\mathbf{\%}$ & $\mathbf{n}^{\mathbf{0}}$ & $\mathbf{\%}$ & $\mathbf{n}^{\mathbf{0}}$ & $\mathbf{\%}$ & $\mathbf{n}^{\mathbf{0}}$ & $\mathbf{\%}$ \\
\hline $\mathbf{1 8 0 5 - 1 8 4 8}$ & 242 & 47,4 & 36 & 7,0 & 233 & 45,6 & 511 & 100,0 \\
$\mathbf{1 8 4 9 - 1 8 7 1}$ & 138 & 63,6 & 13 & 6,0 & 66 & 30,4 & 217 & 100,0 \\
Total & 380 & 52,2 & 49 & 6,7 & 299 & 41,1 & 728 & 100,0 \\
\hline
\end{tabular}

Fontes: Livros de batismos de escravos da llha Grande, 1805-1847 e 1850-1861; Livro de batismos de escravos de Mambucaba, 1830-1871; Livro de batismos de escravos da Ribeira, 1824-1826; e Livro de batismos, casamentos e óbitos de escravos e de livres de Jacuecanga, 1800-1888. Convento do Carmo e Igreja de Jacuecanga, Angra dos Reis, RJ.

Nota: Em um batismo, o padrinho foi Santo Glorioso São Sebastião, seis padrinhos não foram citados e, em sete cerimônias, as situações sociais dos padrinhos estavam ilegíveis.

Buscar padrinhos escravos era, antes de tudo, selecionar indivíduos portadores de vivência e experiência calcadas no cativeiro, uma opção que possibilitava laços de compadrio com outros cativos, constituindo-se ou reforçando-se laços de amizade, trocas e favores entre "iguais". No entanto, os homens livres também tiveram uma importante participação nos batismos de crianças legítimas, principalmente entre 1805 e 1848 . Acreditamos que a opção pelo compadrio com indivíduos livres teria ocorrido em famílias que, já dispondo de redes de amizade no interior da comunidade escrava, desejavam estreitar seus contatos com o "mundo" dos livres.

No caso dos batismos de filhos naturais, os homens livres foram maioria entre os padrinhos, estando presentes em 54,6\% das cerimônias realizadas entre 1805 e 1871; os escravos, por sua vez, estiveram em $40,8 \%$; e os forros, em 4,6\%. Analisando-se os informes a partir da divisão entre a primeira e a segunda metade do século XIX, constatamos que, entre 1805 e 1848 , os cativos foram representados em $34,2 \%$ dos batismos; os forros, em 6,1\%; e os livres, em 59,7\%; e entre 1849 e 1871, os percentuais foram, respectivamente, de $46,5 \%, 3,4 \%$ e $50,1 \%$, dados que se reúnem na Tabela 4. Portanto, também entre as famílias formadas por mães solteiras, os padrinhos cativos foram, ao longo do tempo, cada vez mais convidados a participar do compadrio. 
Tabela 4

Situação social de padrinhos de crianças escravas ilegítimas

por subperíodos

Angra dos Reis, 1805-1871

\begin{tabular}{l|rr|rr|rr|ccc}
\hline Subperíodos & \multicolumn{2}{|c|}{ Escravos } & \multicolumn{2}{c|}{ Forros } & \multicolumn{2}{c|}{ Livres } & \multicolumn{2}{c}{ Total } \\
& $\mathbf{n}^{\mathbf{0}}$ & $\mathbf{\%}$ & $\mathbf{n}^{\mathbf{0}}$ & $\mathbf{\%}$ & $\mathbf{n}^{\mathbf{0}}$ & $\mathbf{\%}$ & $\mathbf{n}^{\mathbf{0}}$ & $\%$ \\
\hline $\mathbf{1 8 0 5 - 1 8 4 8}$ & 383 & 34,2 & 68 & 6,1 & 668 & 59,7 & 1119 & 100 \\
$\mathbf{1 8 4 9 - 1 8 7 1}$ & 618 & 46,5 & 45 & 3,4 & 667 & 50,1 & 1330 & 100 \\
Total & 1001 & 40,8 & 113 & 4,6 & 1335 & 54,6 & 2449 & 100 \\
\hline
\end{tabular}

Fontes: Livros de batismos de escravos da Ilha Grande, 1805-1847 e 1850-1861; Livro de batismos de escravos de Mambucaba, 1830-1871; Livros de batismos de escravos da Ribeira, 1824-1826; e Livro de batismos, casamentos e óbitos de escravos e de livres de Jacuecanga, 1800-1888. Convento do Carmo e Igreja de Jacuecanga, Angra dos Reis, RJ.

Nota: Em 14 cerimônias, os padrinhos não foram citados e, em 10, seus nomes estavam ilegíveis.

Investigados os senhores dos padrinhos escravos de crianças legítimas, constatamos que eram, predominantemente, os mesmos dos pais dos batizandos. No período em estudo, pais e padrinhos pertencentes ao mesmo senhor participaram de $63 \%$ das cerimônias, enquanto, em $37 \%$, os proprietários foram diferentes. Na primeira metade do século (1805-1848), 58,8\% de afilhados e de padrinhos pertenciam ao mesmo senhor, e 41,2\% viviam em escravarias diferentes; e de 1849 a 1871 , foram, respectivamente, $69,9 \%$ e $30,1 \%$. É o que mostra a Tabela 5 . Em arremate, o aumento de protetores escravos teria sido representado pela elevação de compadres pertencentes à mesma propriedade, o que talvez tivesse ocorrido em médias ou grandes propriedades, onde a oferta de escravos era maior. ${ }^{39}$

Quando as famílias legitimadas pelo casamento escolheram compadres escravos de um mesmo senhor, buscaram reforçar a inserção de seus filhos e o fortalecimento dos laços de amizade e de solidariedade dentro dos limites das propriedades em que atuavam. Ao longo do tempo, à medida que o percentual de escravos como padrinhos aumentou, elevou-

\footnotetext{
39 Na freguesia de Inhaúma, no Rio de Janeiro, constatou-se que os cativos pertencentes às maiores propriedades buscaram mais padrinhos e madrinhas entre os cativos de seus próprios senhores. Góes, $O$ cativeiro.
} 
Tabela 5

Senhores de padrinhos escravos e de pais de crianças escravas legítimas batizadas por subperíodos

Angra dos Reis, 1805-1871

\begin{tabular}{l|rc|cc|cc}
\hline Subperíodos & \multicolumn{2}{|c|}{ Senhores iguais } & \multicolumn{2}{|c|}{ Senhores diferentes } & \multicolumn{2}{|c}{ Total } \\
& $\mathbf{n}^{\mathbf{0}}$ & $\mathbf{\%}$ & $\mathbf{n}^{\mathbf{0}}$ & $\mathbf{\%}$ & $\mathbf{n}^{\mathbf{0}}$ & $\mathbf{\%}$ \\
\hline $\mathbf{1 8 0 5 - 1 8 4 8}$ & 134 & 58,8 & 94 & 41,2 & 228 & 100,0 \\
$\mathbf{1 8 4 9 - 1 8 7 1}$ & 95 & 69,9 & 41 & 30,1 & 136 & 100,0 \\
Total & 229 & 63,0 & 135 & 37,0 & 364 & 100,0 \\
\hline
\end{tabular}

Fontes: Livros de batismos de escravos da Ilha Grande, 1805-1847 e 1850-1861; Livro de batismos de escravos de Mambucaba, 1830-1871; Livro de batismos de escravos da Ribeira, 1824-1826; e Livro de batismos, casamentos e óbitos de escravos e de livres de Jacuecanga, 1800-1888. Convento do Carmo e Igreja de Jacuecanga, Angra dos Reis, RJ.

Nota: Em 13 batismos, os proprietários dos batizandos não foram citados e, em três, seus nomes estavam ilegíveis.

-se a frequência daqueles de um mesmo senhor. No caso de estarem em propriedades de menor porte, mais fácil seria essa seleção de padrinhos. Vale lembrar que, tal como visto na Tabela 1, o percentual de grandes propriedades (20 ou mais cativos) diminuiu ao longo da centúria. Deve-se ainda lembrar que a escolha poderia ter resultado de algum grau de interferência de seus senhores.

No batismo de crianças naturais, as mães selecionaram compadres pertencentes a outras propriedades em $58,4 \%$ dos sacramentos realizados entre 1805 e 1871, enquanto padrinhos escravos e afilhados naturais de iguais propriedades foram vistos em $41,6 \%$ das cerimônias. ${ }^{40} \mathrm{Na}$ comparação entre a primeira e a segunda metade do século XIX, elevou-se o percentual de padrinhos escravos, aumento relacionado com a maior representatividade de escravos de diferentes propriedades. Entre $1805 \mathrm{e}$ 1848, padrinhos e afilhados pertencentes ao mesmo senhor representaram $44,3 \%$ das cerimônias, reduzindo-se um pouco (40\%) no segundo subperíodo. No caso de compadres de diferentes senhores, os percentuais foram $55,7 \%$ e $60 \%$, respectivamente (Tabela 6 ).

Frequentemente, as mães solteiras convidavam indivíduos fora

\footnotetext{
40 Comportamento diferente do encontrado para as crianças legítimas.
} 
Tabela 6

Senhores de padrinhos escravos e de mães de crianças escravas ilegítimas por subperíodos

Angra dos Reis, 1805-1871

\begin{tabular}{|c|c|c|c|c|c|c|}
\hline \multirow[t]{2}{*}{ Subperíodos } & \multicolumn{2}{|c|}{ Senhores iguais } & \multicolumn{2}{|c|}{ Senhores diferentes } & \multicolumn{2}{|c|}{ Total } \\
\hline & $n^{0}$ & $\%$ & $n^{0}$ & $\%$ & $n^{0}$ & $\%$ \\
\hline $1805-1848$ & 158 & 44,3 & 199 & 55,7 & 357 & 100,0 \\
\hline $1849-1871$ & 233 & 40,0 & 349 & 60,0 & 582 & 100,0 \\
\hline Total & 391 & 41,6 & 548 & 58,4 & 939 & 100,0 \\
\hline \multicolumn{7}{|c|}{$\begin{array}{l}\text { Fontes: Livros de batismos de escravos da llha Grande, 1805-1847 e 1850-1861; Livro de batismos de } \\
\text { escravos de Mambucaba, 1830-1871; Livro de batismos de escravos da Ribeira, 1824-1826; } \\
\text { e Livro de batismos, casamentos e óbitos de escravos e de livres de Jacuecanga, 1800-1888. } \\
\text { Convento do Carmo e Igreja de Jacuecanga, Angra dos Reis, RJ. }\end{array}$} \\
\hline \multicolumn{7}{|c|}{$\begin{array}{l}\text { Nota: Os proprietários de padrinhos não foram citados em } 60 \text { batismos e, em 2, seus nomes estavam } \\
\text { ilegíveis. }\end{array}$} \\
\hline
\end{tabular}

do universo escravo e, quando a escolha recaía sobre cativos, eles eram de propriedades diferentes. Ambos os processos tinham um ponto em comum: a decisão de abrir os vínculos para além das propriedades em que habitavam, independentemente de assumirem compadrio com livres ou com escravos, embora isso pudesse ser explicado pelo fato de não disporem de oferta suficiente de possíveis padrinhos nas propriedades em que viviam, sobretudo quando fossem de menor porte, em que os cativos existentes já estavam inseridos em laços de amizade e de parentesco.

Quanto à situação social das madrinhas de crianças legítimas (Tabela 7), em 59\% dos batismos elas foram escravas; em 34\%, livres; e, em $7 \%$, foram forras. Observando-se os dados para a primeira e a segunda metade dos Oitocentos, encontramos: 51,3\% de escravas na qualidade de madrinhas, 7,7\% de forras e $41 \%$ de livres. Entre 1849 e 1871 registraram-se, respectivamente, $79 \%, 5,6 \%$ e $15,4 \%$, tendo havido um aumento de cativas como comadres.

Assim como entre os padrinhos, os casais escravos que viviam em Angra dos Reis escolheram madrinhas escravas, mulheres conhecedoras da realidade destinada ao afilhado. Além disso, o percentual de opção por escravas aumentou até 1871 , demonstrando o reforço do compadrio com outros escravos, fortalecendo amizades em meio às adversidades 
Tabela 7

Situação social de madrinhas de crianças escravas legítimas por subperíodos

Angra dos Reis, 1805-1871

\begin{tabular}{l|cc|rr|rr|rc}
\hline Subperíodos & \multicolumn{2}{|c|}{ Escravas } & \multicolumn{2}{c|}{ Forras } & \multicolumn{2}{c|}{ Livres } & \multicolumn{2}{c}{ Total } \\
& $\mathbf{n}^{\mathbf{0}}$ & $\mathbf{\%}$ & $\mathbf{n}^{\mathbf{0}}$ & $\mathbf{\%}$ & $\mathbf{n}^{\mathbf{0}}$ & $\mathbf{\%}$ & $\mathbf{n}^{\mathbf{0}}$ & $\mathbf{\%}$ \\
\hline $\mathbf{1 8 0 5}-1848$ & 221 & 51,3 & 33 & 7,7 & 177 & 41,0 & 431 & 100,0 \\
$\mathbf{1 8 4 9 - 1 8 7 1}$ & 128 & 79,0 & 9 & 5,6 & 25 & 15,4 & 162 & 100,0 \\
Total & 349 & 59,0 & 42 & 7,0 & 202 & 34,0 & 593 & 100,0 \\
\hline
\end{tabular}

Fontes: Livros de batismos de escravos da Ilha Grande, 1805-1847 e 1850-1861; Livro de batismos de escravos de Mambucaba, 1830-1871; Livro de batismos de escravos da Ribeira, 1824-1826; e Livro de batismos, casamentos e óbitos de escravos e de livres de Jacuecanga, 1800-1888. Convento do Carmo e Igreja de Jacuecanga, Angra dos Reis, RJ.

Nota: Em 119 cerimônias, as madrinhas foram santas, em 20 batismos, as madrinhas não foram citadas e, em 10, suas situações sociais estavam ilegíveis.

do sistema. Embora acreditemos que a grande frequência de batismos simples demonstrasse uma menor intervenção senhorial, não podemos esquecer que esses homens e mulheres pertenciam a outrem, estando, portanto, vulneráveis às vontades de seus proprietários. Talvez tenha havido o desejo senhorial de que suas "peças" estabelecessem e reforçassem laços com companheiros de cativeiro. Adiante, veremos que grande parte das madrinhas, independentemente do período, eram do mesmo plantel de seus afilhados.

Como consta na Tabela 8 , no período de 1805 a 1848 , as mães solteiras optaram por comadres escravas em $41,5 \%$ das cerimônias; por forras, em 6,5\%; e, por livres, em 52\%; no período de 1849 a 1871, os percentuais foram, respectivamente: $63,1 \%, 4,2 \%$ e $32,7 \%$. Somando-se os dados dos dois períodos, as madrinhas escravas estiveram presentes em 51,7\%; as forras, em 5,4\%; e as livres, em 42,9\%. Desse modo, como entre as famílias legítimas, esses dados apontam para a preferência por madrinhas escravas com a chegada da segunda metade do século, podendo-se concluir que, durante o acirramento da crise econômica, as mães solteiras passaram a se interessar pela formação de laços com mulheres conhecedoras da realidade do cativeiro. 
Tabela 8

Situação social de madrinhas de crianças escravas ilegítimas por subperíodos

Angra dos Reis, 1805-1871

\begin{tabular}{l|cc|cc|cc|cc}
\hline Subperíodo & \multicolumn{2}{|c|}{ Escravas } & \multicolumn{2}{c|}{ Forras } & \multicolumn{2}{c|}{ Livres } & \multicolumn{2}{c}{ Total } \\
& $\mathbf{n}^{\mathbf{0}}$ & $\mathbf{\%}$ & $\mathbf{n}^{\mathbf{0}}$ & $\mathbf{\%}$ & $\mathbf{n}^{\mathbf{0}}$ & $\mathbf{\%}$ & $\mathbf{n}^{\mathbf{0}}$ & $\mathbf{\%}$ \\
\hline $\mathbf{1 8 0 5}-1848$ & 373 & 41,5 & 58 & 6,5 & 467 & 52,0 & 898 & 100,0 \\
$\mathbf{1 8 4 9 - 1 8 7 1}$ & 507 & 63,1 & 34 & 4,2 & 263 & 32,7 & 804 & 100,0 \\
Total & 880 & 51,7 & 92 & 5,4 & 730 & 42,9 & 1702 & 100,0 \\
\hline
\end{tabular}

Fontes: Livros de batismos de escravos da llha Grande, 1805-1847 e 1850-1861; Livro de batismos de escravos de Mambucaba, 1830-1871; Livro de batismos de escravos da Ribeira, 1824-1826; e Livro de batismos, casamentos e óbitos de escravos e de livres de Jacuecanga, 1800-1888. Convento do Carmo e Igreja de Jacuecanga, Angra dos Reis, RJ.

Nota: Em 694 batismos, as madrinhas foram santas, em 57 as madrinhas não foram citadas e em 20 suas situações sociais estavam ilegíveis.

Além disso, famílias legítimas e ilegítimas também recorreram às chamadas protetoras espirituais para seus filhos.

A Tabela 9 demonstra que, nas 119 cerimônias com madrinha espiritual de crianças legítimas em todo o período, Nossa Senhora foi indicada em 53,8\% dos casos; Santa Ana, em 26,9\%; Nossa Senhora do Rosário, em 15,1\%; Nossa Senhora da Conceição, em 3,4\%; e Nossa Senhora do Bom Despacho, em 0,8\%. Entre os anos de 1805 e 1848, Nossa Senhora foi anotada em $29,2 \%$ de todos esses batismos, indicada em registros de todas as freguesias; Santa Ana foi citada em cerimônias da Ilha Grande (37\%), freguesia que recebia o seu nome; Nossa Senhora do Rosário foi a protetora espiritual em 26,1\% das cerimônias batismais, todas realizadas em Mambucaba, freguesia que levava o seu nome; Nossa Senhora da Conceição, em 6,2\% dos batismos, todos realizados na freguesia de Nossa Senhora da Conceição da Ribeira; e Nossa Senhora do Bom Despacho foi citada em $1,5 \%$. Portanto, durante esses anos, houve uma relativa correspondência entre as madrinhas espirituais e as representações religiosas evocadas nas respectivas freguesias. No segundo subperíodo, excluindo-se os oito batismos da Ilha Grande, nos quais Santa Ana foi lembrada, e um, realizado em Mambucaba, que anotou Nossa Senhora do Rosário como protetora, Nossa Senhora foi a mais indicada como madrinha espiritual $(83,3 \%)$. 


\section{Tabela 9}

Representações religiosas nos batismos de crianças escravas legítimas por subperíodos

Angra dos Reis, 1805-1871

\begin{tabular}{|c|c|c|c|c|c|c|c|c|c|c|c|}
\hline \multirow[t]{2}{*}{ Subperíodos } & \multicolumn{2}{|c|}{ SA } & \multicolumn{2}{|c|}{ NS } & \multicolumn{2}{|c|}{$\mathrm{SC}$} & \multicolumn{2}{|c|}{ SR } & \multicolumn{2}{|c|}{ BD } & Total \\
\hline & $\mathbf{n}^{\mathbf{0}}$ & $\%$ & & $\%$ & $n^{0}$ & $\%$ & $\mathbf{n}^{0}$ & $\%$ & $n^{0}$ & $\%$ & $n^{0} \quad \%$ \\
\hline $1805-1848$ & 24 & 37,0 & 19 & 29,2 & 4 & 6,2 & 17 & 26,1 & 1 & 1,5 & 65100,0 \\
\hline $1849-1871$ & 8 & 14,8 & 45 & 83,3 & 0 & & 1 & 1,9 & 0 & & 54100,0 \\
\hline Total & 32 & 26,9 & 64 & 53,8 & 4 & 3,4 & 18 & 15,1 & 1 & 0,8 & 119100,0 \\
\hline
\end{tabular}

Fontes: Livros de batismos de escravos da llha Grande, 1805-1847 e 1850-1861; Livro de batismos de escravos de Mambucaba, 1830-1871; Livro de batismos de escravos da Ribeira, 1824-1826; e Livro de batismos, casamentos e óbitos de escravos e de livres de Jacuecanga, 1800-1888. Convento do Carmo e Igreja de Jacuecanga, Angra dos Reis, RJ.

Notas: $\mathrm{SA}=$ Santa Ana; NS=Nossa Senhora; $\mathrm{SC}=$ Senhora da Conceição; $\mathrm{SR}=$ Senhora do Rosário; $\mathrm{BD}=$ Senhora do Bom Despacho.

Tabela 10

Representações religiosas nos batismos de crianças escravas ilegítimas por subperíodos

Angra dos Reis, 1805-1871

\begin{tabular}{|c|c|c|c|c|c|c|c|c|c|c|c|}
\hline \multirow[t]{2}{*}{ Subperíodos } & \multicolumn{2}{|c|}{$\mathbf{S A}$} & \multicolumn{2}{|c|}{ NS } & \multirow{2}{*}{$\begin{array}{c}\mathrm{SC} \\
\text { n }^{\circ} \%\end{array}$} & \multicolumn{2}{|c|}{ SR } & \multirow{2}{*}{\begin{tabular}{|c|} 
SB \\
$n^{\circ} \%$ \\
\end{tabular}} & \multirow{2}{*}{$\begin{array}{c}\text { SD } \\
\text { n }^{\circ} \%\end{array}$} & \multirow{2}{*}{\begin{tabular}{c|c|} 
SP \\
n $^{0} \%$
\end{tabular}} & \multirow{2}{*}{$\begin{array}{l}\text { Total } \\
\text { n }^{\circ} \%\end{array}$} \\
\hline & & $\%$ & $\mathbf{n}^{\mathbf{o}}$ & $\%$ & & $n^{0}$ & $\%$ & & & & \\
\hline & 62 & ( & 61 & 34 & 126,7 & 43 & 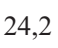 & 0 & 0 & 0 & 17 \\
\hline 1849 & 58 & 8,4 & 427 & 61,5 & 60,9 & 18 & 2 , & 10,1 & 50,7 & 10,1 & 516100 \\
\hline Total & 120 & 17,3 & 488 & 70,3 & $18 \quad 2,6$ & 61 & 8,8 & 10,1 & $\begin{array}{ll}5 & 0,7\end{array}$ & 10,1 & 694100 \\
\hline
\end{tabular}

Fontes: Livros de batismos de escravos da Ilha Grande, 1805-1847 e 1850-1861; Livro de batismos de escravos de Mambucaba, 1830-1871; Livro de batismos de escravos da Ribeira, 1824-1826; e Livro de batismos, casamentos e óbitos de escravos e de livres de Jacuecanga, 1800-1888. Convento do Carmo e Igreja de Jacuecanga, Angra dos Reis, RJ.

Notas: $\mathrm{SA}=$ Santa Ana; NS=Nossa Senhora; $S C=$ Senhora da Conceição; $S R=$ Senhora do Rosário; $\mathrm{SB}=$ Senhora de Belém; $\mathrm{SD}=$ Senhora das Dores; $\mathrm{SP}=$ Senhora do Parto.

O elevado número (119) de protetoras espirituais revelaria uma demonstração de devoção por parte dos pais, ou, ainda, uma possível interferência do pároco que oficiou as cerimônias batismais.

No que concerne a protetoras espirituais de filhos ilegítimos, entre 1805 e 1871, Nossa Senhora foi indicada em 70,3\% dos batismos; Santa Ana, em 17,3\%, todos realizados na Ilha Grande; Nossa Senhora do Ro- 
Tabela 11

Senhores de madrinhas escravas e de pais de crianças escravas legítimas por subperíodos

Angra dos Reis, 1805-1871

\begin{tabular}{l|cc|cc|cc}
\hline Subperíodos & \multicolumn{2}{|c|}{ Senhores iguais } & \multicolumn{2}{c|}{ Senhores diferentes } & \multicolumn{2}{|c}{ Total } \\
& $\mathbf{n}^{\mathbf{0}}$ & $\mathbf{\%}$ & $\mathbf{n}^{\mathbf{0}}$ & $\mathbf{\%}$ & $\mathbf{n}^{\mathbf{0}}$ & $\mathbf{\%}$ \\
\hline $\mathbf{1 8 0 5 - 1 8 4 8}$ & 130 & 62,8 & 77 & 37,2 & 207 & 100,0 \\
$\mathbf{1 8 4 9 - 1 8 7 1}$ & 81 & 64,3 & 45 & 35,7 & 126 & 100,0 \\
Total & 211 & 63,4 & 122 & 36,6 & 333 & 100,0 \\
\hline
\end{tabular}

Fontes: Livros de batismos de escravos da Ilha Grande, 1805-1847 e 1850-1861; Livro de batismos de escravos de Mambucaba, 1830-1871; Livro de batismos de escravos da Ribeira, 1824-1826; e Livro de batismos, casamentos e óbitos de escravos e de livres de Jacuecanga, 1800-1888. Convento do Carmo e Igreja de Jacuecanga, Angra dos Reis, RJ.

Nota: Em 13 cerimônias, os proprietários não foram citados e, em três, seus nomes estavam ilegíveis.

sário, em 8,8\%, realizados em Mambucaba; Nossa Senhora da Conceição foi anotada em 2,6\%, com 10 batismos ocorridos na Ribeira, num total de 694 madrinhas (Tabela 10), cumprindo ressaltar a religiosidade das mães solteiras que, possivelmente, em alguns casos, terão atendido à sugestão dos sacerdotes responsáveis pelas paróquias.

As madrinhas escravas foram uma escolha comum nos batismos de filhos legítimos, como já foi dito. No período 1805-1871, essas mulheres pertenciam majoritariamente à mesma propriedade que os pais de seus afilhados (63,4\% dos casos). Já comadres e casais de diferentes senhores participaram de 36,6\% dos batismos. Entre 1805 e 1848 e de 1849 a 1871 constatamos, para Angra dos Reis, que comadres pertencentes ao mesmo senhor representaram $62,8 \%$ e $64,3 \%$, respectivamente; enquanto comadres de diferentes escravarias corresponderam a $37,2 \%$ e $35,7 \%$. É o que está na Tabela 11.

Comparando a condição jurídica de padrinhos e madrinhas a partir da faixa de tamanho relativa das propriedades, Góes ${ }^{41}$ observou que, na

41 Tratou-se do tamanho relativo, pois o autor realizou uma estimativa dos números de escravos por propriedades, baseando nos números de adultos que compareceram às cerimônias de batismo, na qualidade de batizandos, pais, padrinhos e madrinhas. Portanto, Góes teve acesso ao número mínimo de escravos que pertenciam aos senhores. Ver: Góes, O cativeiro, p. 79. 
Tabela 12

Senhores de madrinhas escravas e de mães de crianças escravas ilegítimas por subperíodos

Angra dos Reis, 1805-1871

\begin{tabular}{l|cc|cc|cc}
\hline Subperíodos & \multicolumn{2}{|c|}{ Senhores iguais } & \multicolumn{2}{|c|}{ Senhores diferentes } & \multicolumn{2}{|c}{ Total } \\
& $\mathbf{n}^{\mathbf{0}}$ & $\mathbf{\%}$ & $\mathbf{n}^{\mathbf{0}}$ & $\mathbf{\%}$ & $\mathbf{n}^{\mathbf{0}}$ & $\mathbf{\%}$ \\
\hline $\mathbf{1 8 0 5 - 1 8 4 8}$ & 145 & 41,8 & 202 & 58,2 & 347 & 100,0 \\
$\mathbf{1 8 4 9 - 1 8 7 1}$ & 184 & 38,6 & 292 & 61,4 & 476 & 100,0 \\
Total & 329 & 40,0 & 494 & 60,0 & 823 & 100,0 \\
\hline
\end{tabular}

Fontes: Livros de batismos de escravos da llha Grande, 1805-1847 e 1850-1861; Livro de batismos de escravos de Mambucaba, 1830-1871; Livro de batismos de escravos da Ribeira, 1824-1826; e Livro de batismos, casamentos e óbitos de escravos e de livres de Jacuecanga, 1800-1888. Convento do Carmo e Igreja de Jacuecanga, Angra dos Reis, RJ.

Nota: Em 57 cerimônias não constavam os nomes dos proprietários.

freguesia rural de Inhaúma, na cidade do Rio de Janeiro, entre 1817 e 1842, à medida que crescia o número de escravos por propriedade, tendia, gradativamente, a aumentar a presença de padrinhos e madrinhas de igual dono.

Tomando de empréstimo essa constatação, podemos especular que os pais que faziam do batismo um momento para estabelecer e reforçar vínculos com escravas que viviam na mesma propriedade de seus futuros afilhados poderiam estar inseridos em escravarias de médio a grande porte, o que facilitava a seleção de comadres entre as escravas pertencentes aos seus senhores. Seus filhos teriam, assim, protetoras que mais de perto poderiam socorrer e apoiar seus futuros afilhados em situações inesperadas, como a separação de pais e filhos, por exemplo. Os laços de compadrio reforçavam amizades e solidariedades, e os de apadrinhamento inseriram as crianças na comunidade.

No caso das crianças ilegítimas, o movimento foi diferente, como se vê na Tabela 12, que permite constatar que as mães solteiras convidaram cativas de outros senhores para serem suas comadres em $60 \%$ dos sacramentos, sendo de $40 \%$ o percentual de mães e comadres de um mesmo senhor. Nos anos de 1805 a 1848, escravas de diferente senhor foram madrinhas em 58,2\% dos batismos e, entre 1849 e 1871 , em $61,4 \%$, sendo $41,8 \%$ e $38,6 \%$, respectivamente, os percentuais de comadres de um mesmo proprietário. 
Cruzando-se os percentuais indicados no parágrafo anterior com aqueles encontrados para as madrinhas escravas, concluímos que o aumento da participação de mulheres cativas como comadres foi acompanhado pela elevação do convite feito às escravas de outros senhores. Ou seja, enquanto as madrinhas escravas de legítimos foram, cada vez mais, escolhidas nas propriedades dos pais, as madrinhas cativas das crianças naturais foram buscadas em propriedades diferentes.

As mães solteiras, ao longo da segunda metade dos Oitocentos, convidaram mais padrinhos escravos, muitos de outras propriedades, ${ }^{42}$ atitude semelhante no que se refere às madrinhas, muitas também de outras escravarias. Com o avanço dos anos, as famílias ilegítimas foram agindo de forma semelhante às legítimas, ou seja, passando a associar-se a membros da comunidade escrava, embora, no caso das primeiras, os cativos fossem buscados em outras propriedades.

\section{Considerações finais}

Com base na elevada frequência de batismos simples, afirmamos, inicialmente, que os laços de compadrio resultaram de decisões escravas. Acreditamos que, em meio ao sistema escravista e às brechas existentes, os cativos fizeram valer algumas de suas vontades. Não obstante, seus senhores deveriam concordar com suas decisões e até mesmo interferir nas escolhas feitas. Portanto, não é nosso objetivo descartar o caráter de propriedade e o poder senhorial, apenas acreditamos que o batismo foi, para muitos dos escravos, a oportunidade de ampliar laços de amizade, tão necessários na dura vida em cativeiro. Nesse aspecto, entendemos que as famílias escravas eram um dos meios para estranhos, ou estrangeiros, tornarem-se conhecidos, estabelecendo a paz, tal como dizem Florentino e Góes ${ }^{43}$ mas era, também, a oportunidade de exercerem a autonomia, tão valiosa para seres que, juridicamente, não tinham o poder sobre seus corpos e destinos. ${ }^{44}$

\footnotetext{
42 Entretanto, as mães solteiras continuaram preferindo padrinhos livres, mas houve uma redução percentual dos mesmos e uma elevação dos convites feitos aos escravos.

43 Florentino e Góes, $A$ paz.

${ }_{44}$ Slenes, Na senzala.
} 
Observamos que o batismo de crianças legítimas se caracterizou, em Angra dos Reis, pela escolha de padrinhos e madrinhas escravos. Padrinhos, madrinhas e afilhados de uma mesma propriedade foram comuns nessas cerimônias, embora tenha havido pais que requisitassem cativos de outras propriedades.

As famílias legitimadas que fizeram do ritual do batismo o momento para o estabelecimento de laços com outros cativos do mesmo plantel deveriam, possivelmente, pertencer a médias ou grandes propriedades.

Em menor número, mas não menos importante, foram os padrinhos e madrinhas escravos pertencentes a outras propriedades, o que representava a opção pelo alargamento dos conhecimentos e contatos daquelas famílias para além das propriedades em que viviam. Seus senhores poderiam ser, por exemplo, vizinhos ou até mesmo parentes.

Entretanto, houve uma participação importante dos padrinhos livres. As famílias que se associavam em compadrio com pessoas livres buscavam ampliar seu raio de ação. Algumas dessas famílias já teriam, talvez, uma intensa rede de contatos entre os seus "irmãos" de cativeiro e estivessem vivendo um processo de abertura rumo ao universo livre.

As famílias formadas por mães solteiras escolheram predominantemente, em todos os subperíodos, padrinhos livres. Já as madrinhas livres foram mais comuns nos anos até 1848. Em outras palavras, quando as mães solteiras optaram por compadres e comadres, convidaram indivíduos em situação jurídica superior, tendo entre eles alguns proprietários de outros escravos, tenentes, capitães, alferes, etc. Entre as madrinhas, além das cativas, também estavam mulheres que tinham à frente de seus nomes a classificação de Dona. ${ }^{45}$

Muitas mães solteiras deveriam estar em convívio com homens e mulheres livres, o que gerava uma aproximação entre eles e até amizades e afetividades. Muitas poderiam viver em propriedades com reduzido número de escravos, facilitando seus contatos com, por exemplo, parentes de seus proprietários.

Gradativamente, a participação de madrinhas livres diminuiu e

45 Vasconcellos, “Famílias escravas", pp. 164-210. 
elevou-se nos documentos consultados a referência às escravas após 1849. Esse movimento foi acompanhado de uma maior frequência no convite feito às mulheres pertencentes a outras propriedades.

Não obstante as diferenças verificadas entre as famílias legítimas e ilegítimas, ambas convidavam, mais e mais, escravos para participar do batismo de seus filhos. Comparando os informes para os anos 18051848 e 1849-1871, observamos um aumento na incidência de compadres e comadres escravos, particularmente de plantéis diferentes. Em meio às transformações verificadas com a chegada da segunda metade dos Oitocentos, elevou-se a frequência de protetores cativos. Acompanhando esse processo, foi se estabelecendo uma comunidade cativa ${ }^{46}$ que ia além das propriedades, acompanhada de redução do número de escravos e elevação da frequência de crioulos, pois, no ano de $1852,62,6 \%$ dos cativos eram nascidos no Brasil, aumentando para $82,9 \%$ em $1872 .{ }^{47}$

Portanto, em meio a mudanças econômicas e demográficas em Angra dos Reis, os cativos adotaram o compadrio com outros escravos, particularmente de propriedades diferentes, reforçando amizades e alianças, criando uma comunidade extraplantel, caracterizada por diferenças de várias naturezas como qualquer comunidade, mas formada por indivíduos que já tinham uma vivência no cativeiro que deveria remontar, no mínimo, a uma geração. A mobilidade espacial vivenciada por esses indivíduos facilitava o conhecimento e os contatos e permitia que homens e mulheres pudessem dividir esperanças e angústias, dois sentimentos presentes no sistema escravista.

Texto recebido em 31 de março de 2013 e aprovado em 10 de outubro de 2013

\footnotetext{
${ }^{46}$ A ideia de comunidade escrava foi trabalhada por Góes, em estudo sobre Inhaúma, no Rio de Janeiro. Ver: Góes, O cativeiro. Mais recentemente, Engeman, em pesquisa sobre a Fazenda Santa Cruz, antiga propriedade jesuítica que, após a expulsão da Companhia de Jesus de Portugal e seu Império, em 1759, passou para a Coroa, observou a existência de uma comunidade escrava na propriedade. Ver: Engeman, De laços.

47 Vasconcellos, "Famílias escravas", p. 66.
} 


\title{
Resumo
}

O artigo trata dos laços de compadrio e de apadrinhamento criados por escravos em Angra dos Reis, entre os anos de 1805 e 1871. Foram utilizados 3.264 registros paroquiais de crianças existentes no Convento do Carmo e na Igreja de Jacuecanga, ambos localizados em Angra dos Reis, e 220 inventários post-mortem armazenados no Museu da Justiça do Rio de Janeiro e no Arquivo Nacional. Na região, ao longo da segunda metade do século XIX, houve um decréscimo do número de escravos. Em meio às transformações econômicas e demográficas, foram observadas as opções efetuadas pelas famílias nucleares e matrifocais quanto à escolha de protetores espirituais para seus filhos.

Palavras-chave: famílias escravas - litoral sul-fluminense - movimento portuário

\begin{abstract}
The article discusses the ties between parents and godparents created by slaves in Angra dos Reis, between the years 1805 and 1871. Three thousand two hundred sixty-four parish registers of children existing in the Carmo Convent and Church of Jacuecanga, both located in Angra dos Reis and 220 post-mortem inventories stored at the Museum of Justice of Rio de Janeiro and the National Archives were used. In the region, throughout the second half of the nineteenth century, the number of slaves diminished. Among the economic and demographic changes, there are the options made by matrifocal and nuclear families as the choice of spiritual protectors for their children.
\end{abstract}

Keywords: slave families - southern coast of Rio de Janeiro - sul fluminense - port traffic. 